\title{
The Application of Structural Design in Haute Couture
}

\author{
Lihong Wei ${ }^{1}$
}

${ }^{1}$ Apparel Management Department of Jiangxi Clothing Institute, Nan Chang, Jiang Xi, 330201

KEYWORDS: Structural Design, Haute Couture, Application

\begin{abstract}
Service design is a systematic work, and the high degree of complexity requires designers with a high level of design skills, but also need to have innovative thinking ability, so as to ensure the optimal structure design clothing. For haute couture, the fashion design belongs to a very important branch. To make the quality of haute couture designs are effectively protected, you need to have a high level of designer clothing structure design capabilities. This paper briefly applied to the structural design haute couture significance on the basis of further structural design haute couture application for analysis, hoping to provide some suggestions for optimizing valuable haute couture designs.
\end{abstract}

\section{Introduction}

Design fashion design is particularly important part in ensuring optimization of structural design, basic science on the whole to be able to make the costume design quality has been effectively improved. For haute couture, whether it is in the design, or in the overall quality, all have high standards and requirements [1]. Therefore, in order to make haute couture design has been optimized, it is necessary to have a high level of costume design techniques and methods. In view of this, it is very significant to analyze the paper "The Application of structural design in haute couture ".

\section{The Sense of Using Structure Design in the Haute Couture}

Haute couture clothing design occupies an important position in the design, including the design of three aspects: First, the style design; Second, structural design; Third, process design. Among the structural design there is a significant meaning and effect, mainly because the structural design is based on the extension and development of models of equipment, process design and at the same time also prepares the conditions. For structural design, the design concept can be fully reflected. The haute couture design would require an innovative design concept, while the specific needs and the overall concept of space adoption will be structured overall design is complete, part of the processing between the structure and the structure of an essential correlation program [2]. Therefore, whether from the structural design of the action or haute couture designs from the demand side considerations, structural design haute couture both possess significant.

\section{The Application Analysis of Structural Design in Haute Couture}

For structural design is one of the main components of the equipment belonging to haute couture, the main contents are: three-dimensional modeling based on the whole clothing outline form established by decomposition of haute couture, but also on some of these modeling decomposed further by way of drawings the flat benefits garments unfolded. Thus, the structural design in clothing design correction process, are an essential part. Based on years of design experience, we 
can see the structural design is reasonable, effective for the irrational structure of the relationship between the presence of clothing design is corrected, further effects and quality clothing. Based on advanced clothing design composition structure considerations, structural design can be extended style design, while promoting the development of design styles, and process design, structural design is an essential part of the foundation, so that the starting point for process design. So, for the structural design, the meaning has a central role.

Based on terms of the overall level, the design itself able to design clothing styles structural anatomy, so that two-dimensional or multi-dimensional display to show the clothing style modeling are effectively realized. In other words, the structure of the garment structure design allows even more detailed, specific, make unreasonable modeling clothing and non-standard situation has been effectively corrected [3]. Therefore, the design also includes a review of haute couture design features that enhance the quality of haute couture designed to lay the foundation. All in all, for the designer, the need to fully recognize the value of the role of structural design, structural design and full application in advanced garment equipment, and thus provide protection to enhance the quality and effectiveness of haute couture.

Structural design is two-dimensional or multi-dimensional approach to every part of the garment fully brought out, such as the collar, cuffs and waist information such as the overall garment unfolded [4]. Which shows that design can provide garments designed, and detailed specifications, further advanced clothing equipment are even more rational and scientific as well as with the established structure of the material selection, shape, and haute couture designs vividly demonstrated. At the same time, the structural design, it is a basic component of haute couture design, in which the emphasis on theoretical knowledge of the application, which means that the structure is designed to show the way out through the data, like the help of some people during the design data expansion corresponding activities. As can be appreciated, structural design theory component of clothing needs through practice before the effective conversion for the production model. Before haute couture design, need some data, information as a support, and design just provides a comprehensive specification information for the haute couture design, advanced garment design process includes reference information and materials, and thus to the smooth development of haute couture design laid Foundation.

For clothing, it belongs to a class of goods, in the development process and the design of clothing must meet the basic requirements of the people's size and specifications. It also makes clothing design, pre-production, the need and type of clothing design aspects for the design and specifications of the aspects of design styles. Clothing based on traditional designs, designers only need credentials subjective experience will clothing pattern designed, this design approach makes much the same style of clothing, and then the lack of innovation to a large extent. Since the 21 century, the pursuit of beauty is gradually increasing. Thus, in terms of wearing apparel, people have different requirements and needs. For example, pay attention to innovation and focus on the overall apparel beauty clothing and the like. Architecture design provides a lot of information into garment design specifications, so that even more advanced clothing design standards, more diverse [5]. This is mainly because the structural design is the traditional design pattern of sublimation, considering consumers pay more attention to the structural design of the shape and temperament, then take two or more dimensions corresponding manner designed not only to meet individual needs in terms of wearing apparel, and enabling senior clothing design quality has been effectively improved. So, overall terms, the structural design enables the standardization and diversification haute couture design effectively show. 
In haute couture design structural design applications sometimes pay attention to the structure of "deconstruction." For deconstruction, it refers to the clothing come in handy, so that the clothing on the surface reflects the innovation as well as the audience beautiful role. The main structural design includes the whole way deconstruction and partial dislocation structure. First, the overall deconstruction, it can be traditional external contour costume break, and then create a new external profile. For topical deconstruction is that the structural member for clothing, partial deconstruction and conventional methods typically operate contrary, such as some template wearing denim jacket, the sleeves Sleeve site no clothes piece Long sleeve seam and, but with the uterus buckle fixed. Partial deconstruction is an innovation, is an "unconventional" design. In addition, for dislocation deconstruction, it refers to the replacement of the traditional clothing to other parts of the site. In structural design, dislocation deconstruction is a manifestation of creative thinking, innovation make clothing are effectively outstanding.

From the point of view in terms of the overall structural design haute couture Value effect is remarkable, and can provide information for the development of specifications haute couture design work, while enabling advanced garment design process to master the clothing from multiple dimensions the structure, designed to further make the clothing to meet consumer demand, but also to improve the shortcomings of traditional clothing fashion design.

\section{Conclusion}

Through this study, we are recognizing that structural design is advanced clothing design is a very important part of haute couture design specifications provided played a role. At the same time, the structural design into advanced garment design process, enabling haute couture designs have specific ideas and innovative design solutions, and thus for the smooth development of the design and optimization of the foundation. Therefore, for the fashion, we need to fully understand the advantages of structural design, and with its advantages and further its application to advanced garment design process, and focus on a variety of applications deconstruction haute couture designs, such as the overall deconstruction, Deconstruction and partial dislocation and deconstruction. In short, the structural design of significant advantages desirable in haute couture designs. China's apparel market continues to believe in the development process, the structural design of the application will be able to obtain a valid extension and expansion, further lay a solid foundation for the overall fashion design optimization and improvement.

\section{REFERENCE:}

[1] Gao Lingyun, Qiu Peina. Research on lace in modern clothing design application [J]. Shandong Textile Economy, 2013,06:71-72.

[2] Jiang Runan design method derived from high fashion to clothing products [J] Textile Leader, 2011,06: 92-93.

[3] Chen Xianchang. aesthetic implication of haute couture [J]. Arts Education, 2015,02: 255.

[4] Chen Ying. Tang Haiyang. Song Jin-ocean research in modern fashion design application methods [J]. silk, 2014,04: 53-56.

[5] Xiao Lizhi. Shaw determined garment draping materials and production techniques [J]. Donghua University (Social Science Edition), 2012,04: 231-236. 